\title{
Relation between plasma nitrate and mean pulmonary arterial pressure in ventricular septal defect
}

\author{
J Takaya, M Teraguchi, S Nogi, Y Ikemoto, Y Kobayashi
}

\begin{abstract}
Background-Nitric oxide (NO) is known to modulate myocardial contraction and coronary tone, and its inhalation reduces pulmonary vascular resistance in patients with pulmonary hypertension.

Objectives-To evaluate the pathophysiological role of NO in patients with a ventricular septal defect (VSD).

Patients-Twenty nine children with VSD, nine of whom had undergone VSD closure surgery, and 14 patients with Kawasaki disease. The mean age of the VSD patients was 3.1 years (range, 2 months to 9 years). Methods-Using high performance liquid chromatography, nitrate (a more stable NO oxidation product) was measured in plasma specimens of the patients undergoing cardiac catheterisation.

Results-Nitrate concentrations in the pulmonary artery bore a significant relation to mean pulmonary artery pressure, pulmonary to systemic systolic pressure ratio, and pulmonary to systemic flow ratio.

Conclusions-The concentration of nitrate was in proportion to the increment in intravascular or cardiac pressure, indicating that endogenous NO is upregulated as a compensatory homeostatic attempt to reduce pulmonary pressure and blood flow.

(Arch Dis Child 1998;79:498-501)
\end{abstract}

Keywords: nitrate; nitric oxide; ventricular septal defect

Nitric oxide (NO) is an endothelium derived relaxing factor. In addition to being a vasodilator, NO acts as a bronchodilator ${ }^{1}$ and anticoagulant. ${ }^{2}$ Several studies have shown that inhalation of $\mathrm{NO}$ reduces pulmonary vascular resistance in patients with pulmonary hypertension. ${ }^{3} \mathrm{NO}$ is also known to modulate myocardial contraction and coronary tone. ${ }^{45}$ $\mathrm{NO}$ is produced from L-arginine under the catalytic control of three isoforms of the enzyme, nitric oxide synthase (NOS). Constitutive NOS was reported to exist in the mammalian heart ${ }^{6}$ and to be regulated by the contractile state of the heart or shear stress. ${ }^{78}$ Pulmonary vascular endothelial cells also produce endogenous NO. ${ }^{9}$ Increased pulmonary blood flow raises basal NO production. ${ }^{10}$

Nitrate is one of the NO oxidation products and is regarded as an index of $\mathrm{NO}$ production. ${ }^{11}{ }^{12}$ The role of NO in the modulation of cardiac function is less well character- ised. Therefore we measured plasma nitrate using high performance liquid chromatography (HPLC) to study its relation to mean pulmonary arterial pressure in patients with ventricular septal defect (VSD) as a representative intracardiac shunt disease.

\section{Patients}

Thirty eight subjects with VSD (nine treated surgically, 29 treated medically) were studied; their median age was 3.1 years (range, 2 months to 9 years). Four patients who had been operated on for VSD were examined before and after surgery. Fourteen patients with Kawasaki disease were also studied more than one year after onset. They were healthy except for a past history of Kawasaki disease, and coronary dilatation, or suspected aneurysm. No coronary changes were seen in the patients with Kawasaki disease by echocardiography or cardiac catheterisation at the time of study. None of the patients had renal dysfunction or cardiac diseases other than VSD. They were not on nitrate containing medication. Sixteen patients were on long term digoxin and diuretics but did not take their medications on the day of the study. Pulmonary and femoral arterial blood pressures were determined with indwelling catheters and fluid filled transducers (Mingograf 7; Siemens Elema AB, Solna, Sweden). Heparinised blood was obtained during diagnostic cardiac catheterisation from the femoral artery, left and/or main pulmonary arteries, right atrium, right ventricle, superior vena cava, and inferior vena cava. Five specimens from the right atrium, three from the right ventricle, three from the superior vena cava, and two from the inferior vena cava were not available because of technical problems. Vascular resistance and central shunt were determined with standard formulae, and resistance was indexed to body surface area. ${ }^{13}$ Cardiac output was measured by the Fick principle. ${ }^{14}$ Cardiac index was determined as cardiac output divided by body surface area. Informed consent was obtained from the parents of the patients.

\section{Methods}

Plasma samples were frozen at $-70^{\circ} \mathrm{C}$ until the assay was performed. Deproteination was performed by centrifugation with Centricut (Tosoh, Tokyo, Japan). Plasma was diluted 20 times and $100 \mu \mathrm{l}$ was applied as a sample. Chromatographic analysis was carried out on a Tosoh HPLC computer assisted system. The analytical column was an ion chromatography 
Table 1 Profile of the subjects

\begin{tabular}{llll}
\hline & VSD $(n=29)$ & $\begin{array}{l}\text { VSD after } \\
\text { surgery }(n=9)\end{array}$ & KD $(n=14)$ \\
\hline Male/female & $19 / 10$ & $7 / 2$ & $11 / 3$ \\
Mean (SE) age (years) & $3.1^{\star}(0.5)$ & $3.2(09)$ & $6.5(1.4)$ \\
Mean (SE) PPA (mm Hg) & $21.7^{\star}(1.9)$ & $18.6(1.7)$ & $15.3(1.0)$ \\
Mean (SE) Qp/Qs & $2.14 \dagger(0.25)$ & $1.00(0.05)$ & $0.98(0.04)$ \\
Mean (SE) Pp/Ps & $0.40^{\star}(0.04)$ & $0.28(0.02)$ & $0.24(0.02)$ \\
Mean (SE) Rp/Rs & $0.14(0.02)$ & $0.25 \dagger(0.02)$ & $0.17(0.03)$ \\
Mean (SE) nitrate ( $\mu \mathrm{mol} / \mathrm{l})$ & $38.6^{\star}(5.2)$ & $29.5(9.7)$ & $18.1(4.2)$ \\
Mean $(\mathrm{SE}) \mathrm{CI}\left(\mathrm{litre} / \mathrm{min} / \mathrm{m}^{2}\right)$ & $3.08(0.40)$ & $3.08(0.39)$ & $4.34(0.40)$ \\
Mean $(\mathrm{SE})$ serum creatinine $(\mathrm{mg} / \mathrm{dl})$ & $0.31(0.02)$ & $0.30(0.05)$ & $0.33(0.04)$ \\
\hline
\end{tabular}

${ }^{\star} \mathrm{p}<0.05,+\mathrm{p}<0.005 v$ Kawasaki disease.

$\mathrm{PPA}$, mean pulmonary arterial pressure (normally less than $20 \mathrm{~mm} \mathrm{Hg})^{16} ; \mathrm{Op} / \mathrm{Qs}$, pulmonary to systemic flow ratio (in the absence of a left to right shunt $\mathrm{Qp} / \mathrm{Qs}$ is 1 ); $\mathrm{Pp} / \mathrm{Ps}$, pulmonary to systemic systolic pressure ratio; Rp/Rs, pulmonary to systemic vascular resistance ratio (normally less than 0.3$)^{16}$; CI, cardiac index; KD, Kawasaki disease.

TSK-gel IC-Anion-PW column $(10 \mu \mathrm{m}$ particle size, $50 \mathrm{~mm} \times 4.6 \mathrm{~mm}$ internal diameter) from Tosoh. A sodium chloride solution (15 mM, pH 5.7) was prepared from an analytical grade reagent and pumped through the column at a flow rate of $1.2 \mathrm{ml} /$ minute at room temperature. Standard solutions of sodium nitrite and sodium nitrate were injected into the HPLC system at a constant volume of $100 \mu \mathrm{l}$ and at increasing concentrations. The interassay coefficient of variation $(\mathrm{CV})$ was $1.0 \%$. The HPLC column was calibrated daily using standards.

CHEMICALS AND REAGENTS

Sodium nitrite and sodium nitrate were obtained from Sigma (St Louis, Missouri, USA). HPLC grade distilled water and sodium chloride were from Wako (Osaka, Japan).

\section{STATISTICAL ANALYSIS}

Analysis of variance was used for comparisons between groups. ${ }^{15}$ If significant, group means were compared by the two tailed $t$ test for groups of unpaired observations. Differences were considered significant at a probability level of $<0.05$. Group data were expressed as means (SE).

\section{Results}

With our chromatographic procedure, sodium nitrite and sodium nitrate had a retention time of $4.2(0.2)$ and $6.8(0.3)$ minutes, respectively. The assay was found to be linear over the 0-35 $\mu \mathrm{mol} / 1$ range, with a mean regression correlation coefficient of 0.9 (not shown). Chromatograms obtained after the injection of a plasma specimen diluted $1 / 20$ into the HPLC system yielded a significant increase in the concentration of nitrate but not of nitrite.

The clinical data of the study subjects are shown in table 1 . The mean age of the VSD group was younger than that of the Kawasaki disease group. The mean pulmonary arterial pressure, pulmonary to systemic flow ratio (Qp/Qs), pulmonary to systemic systolic pressure ratio $(\mathrm{Pp} / \mathrm{Ps})$, and nitrate concentration in the left and/or main pulmonary arteries in the VSD group were higher than in the Kawasaki disease group. The pulmonary to systemic vascular resistance ratio $(\mathrm{Rp} / \mathrm{Rs})$ in the postoperative VSD group was higher than in the Kawasaki disease group. Pooled mean pulmonary vascular resistance in the VSD, postopera-

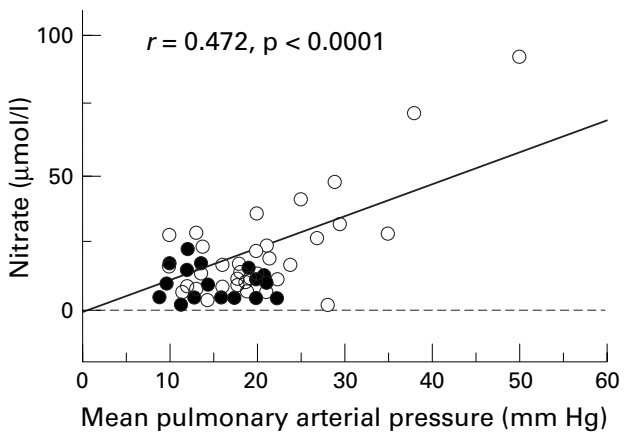

Figure 1 Relation between plasma nitrate in pulmonary arteries and mean pulmonary arterial pressure. Open circles, VSD; closed circles, Kawasaki disease.

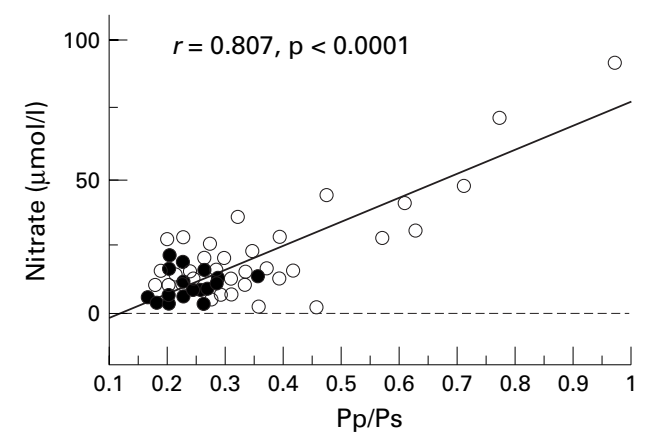

Figure 2 Relation between plasma nitrate in pulmonary arteries and pulmonary to systemic systolic pressure ratio (Pp/Ps). Open circles, VSD; closed circles, Kawasaki disease.

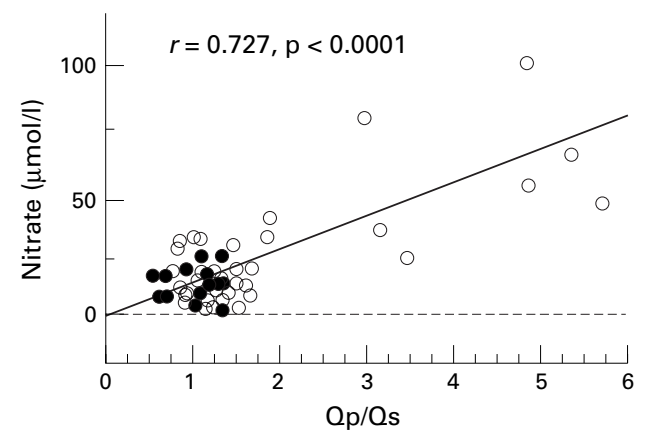

Figure 3 Relation between plasma nitrate in pulmonary arteries and pulmonary to systemic flow ratio $(Q p / Q s)$. Open circles, VSD; closed circles, Kawasaki disease.

tive VSD, and Kawasaki disease groups was 3.1 (0.6), 4.1 (0.9), and 2.0 (0.2) $\mathrm{mm} \mathrm{Hg} / \mathrm{l} /$ minute, respectively; pulmonary vascular resistance in the postoperative VSD group was significantly higher than that in the Kawasaki disease group $(\mathrm{p}<0.01)$. Systemic resistance in the VSD, postoperative VSD, and Kawasaki disease groups was $26.0(2.0), 21.2$ (1.2), and 21.0 (1.3) $\mathrm{mm} \mathrm{Hg} / \mathrm{l} / \mathrm{minute}$, respectively. No significant difference of systemic resistance was seen among the three groups. Other parameters between the groups were comparable. No correlation was seen between nitrate concentrations and age.

Specimens of the Kawasaki disease patients were drawn from fewer points-pulmonary artery $(n=13)$, inferior vena cava $(n=9)$, femoral artery $(n=9)$, and superior vena cava $(n=9)$. Mean nitrate values of the VSD group were significantly higher than those of the Kawasaki disease group only in the pulmonary 
Table 2 Comparison of parameters: before and after surgery for VSD

\begin{tabular}{|c|c|c|c|c|c|c|}
\hline Patient & Age (months) & $\begin{array}{l}\text { Nitrate in } P A \\
(\mu \mathrm{mol} / \mathrm{l})\end{array}$ & $\begin{array}{l}P P A \\
(m m \mathrm{Hg})\end{array}$ & $Q p / Q s$ & $P p / P s$ & $R p / R s$ \\
\hline \multirow[t]{2}{*}{1} & Before (4) & 100 & 29 & 4.84 & 0.71 & 0.15 \\
\hline & After (12) & 22 & 14 & 1.07 & 0.27 & 0.20 \\
\hline \multirow{2}{*}{2} & Before (5) & 55 & 35 & 1.82 & 0.57 & 0.33 \\
\hline & After (36) & 30 & 18 & 1.05 & 0.31 & 0.24 \\
\hline \multirow[t]{2}{*}{3} & Before (2) & 50 & 50 & 4.81 & 0.97 & 0.21 \\
\hline & After (16) & 39 & 16 & 1.00 & 0.31 & 0.31 \\
\hline \multirow[t]{2}{*}{4} & Before (48) & 39 & 10 & 1.07 & 0.20 & 0.05 \\
\hline & After (70) & 22 & 18 & 1.00 & 0.22 & 0.26 \\
\hline
\end{tabular}

PA, pulmonary artery; PPA, mean pulmonary arterial pressure; $\mathrm{Pp} / \mathrm{Ps}$, pulmonary to systemic systolic pressure ratio; $\mathrm{Qp} / \mathrm{Qs}$, pulmonary to systemic flow ratio; $\mathrm{Rp} / \mathrm{Rs}$, pulmonary to systemic vascular resistance ratio (normally less than 0.3 ).

artery. The pooled nitrate concentrations of each site were as follows: femoral artery, 26.4 (1.1); left and/or main pulmonary arteries, 35.0 (6.3); right atrium, 36.6 (6.6); right ventricle, 34.3 (5.3); superior vena cava, 31.9 (6.0); and inferior vena cava, $27.2(4.3) \mu \mathrm{mol} / 1$. No significant difference in nitrate concentrations was observed among sampling sites.

In all the patients, mean pulmonary arterial pressure was positively correlated with nitrate in all sampling sites $(\mathrm{p}<0.05)$. Figure 1 shows the correlation between mean pulmonary arterial pressure and nitrate in the pulmonary artery. The nitrate concentrations in the pulmonary artery (fig 2), right atrium, right ventricle, inferior vena cava, and superior vena cava were positively correlated with $\mathrm{Pp} / \mathrm{Ps}$. The plasma nitrate concentration in the left and/or main pulmonary arteries correlated positively with Qp/Qs ( $<<0.0001$; fig 3). In the four patients who were studied before and after surgery for VSD, nitrate in the pulmonary artery decreased after surgery. Nitrate was correlated with the reduction of $\mathrm{Qp} / \mathrm{Qs}$ in all the patients (table 2). The nitrate concentration did not correlate with pulmonary vascular resistance, systemic resistance, $\mathrm{Rp} / \mathrm{Rs}$, cardiac index, oxygen saturation, or haematocrit results.

\section{Discussion}

We determined plasma nitrate concentrations in patients with VSD to see whether NO production increases in relation to the pulmonary artery pressure or pulmonary blood flow. We found that endogenous NO production was already increased in the patients with VSD (table 1) and that plasma nitrate was positively correlated with mean pulmonary arterial pressure (fig 1). We think, therefore, that raised pulmonary pressure might lead to upregulation of NO production.

Endothelia can respond to raised intravascular or cardiac pressure with an increased NO production. ${ }^{6}$ When pulmonary arterial pressure is raised an enhanced NO production probably acts as a compensatory mechanism in the cardiohaemodynamics of VSD by decreasing myocardial contractility and causing vascular dilatation. This conclusion was supported by the fact that nitrate concentrations were reduced dramatically after surgery for VSD (table 2) and also by a previous report that NO synthesis was higher when systemic arterial pressure was increased. ${ }^{6}$

Although mean pulmonary arterial pressure, $\mathrm{Pp} / \mathrm{Ps}$, and $\mathrm{Rp} /$ Rs were unremarkable, patient 4

\section{Key messages}

- The concentration of nitrate in the pulmonary artery of VSD patients bears a significant relation to both the ratio of pulmonary to systemic systolic pressure $(\mathrm{Pp} / \mathrm{Ps})$ and the ratio of pulmonary to systemic flow $(\mathrm{Qp} / \mathrm{Qs})$

- The concentration of nitrate in the pulmonary artery is reduced dramatically after surgery

- Plasma nitrate might be a good marker of intravascular pressure and pulmonary blood flow

was operated on for perimembranous outlet type VSD to prevent progressive aortic insufficiency. In accordance with a slight decrease in $\mathrm{Qp} / \mathrm{Qs}$, nitrate also decreased after surgery. NO might be regulated not only by pressure but also by blood flow. Myles et al reported that low systemic vascular resistance after cardiac surgery was not associated with endogenous $\mathrm{NO} .{ }^{17}$ Similarly, we did not find any correlation between $\mathrm{Rs} / \mathrm{Rp}$ and nitrate concentrations before and after surgery. No difference in serum creatinine was seen among the three groups (table 1). The increased plasma nitrate concentrations were not caused by the decrease in glomerular filtration rate because serum creatinine values were within the normal range in the patients. Although we did not measure nitrate clearance, we concluded that the increase in nitrate might be a result of its increased production without a reduced clearance.

Iizuka et al reported that urinary nitrite and nitrate concentrations of patients with Kawasaki disease on days 3-21 were higher than those of controls. ${ }^{18}$ It could be argued that comparing VSD patients with those with Kawasaki disease is not appropriate, because the latter disorder is associated with an endothelial dysfunction. This assumption might be valid when the Kawasaki disease patients are in the acute stage, but those at one year after onset are quiescent and could reasonably be regarded to represent a "normal" population.

Pulmonary arterial pressure was positively correlated with plasma nitrate concentrations at all sampling sites. The significance of this observation might indicate that all values on the "right side" of the circulation are globally raised because of a long half life of nitrate. Zeballos et al noted a correlation with production of NO and nitrate concentrations only in the coronary and pulmonary circulation but not in peripheral venous blood. ${ }^{12}$ No significant difference was observed in nitrate concentrations among sampling sites. Although we did not determine nitrate concentrations in peripheral venous blood, they are estimated to be equal to those in the superior vena cava and the inferior vena cava. Therefore, nitrate in systemic blood might be a good predictor of pulmonary arterial pressure. 
Nitrate in the pulmonary artery also showed a good correlation with $\mathrm{Qp} / \mathrm{Qs}$, indicating that not only intravascular or cardiac pressure, but also flow, might contribute to NO production. Reportedly, constitutive NO synthase is regulated by shear stress. ${ }^{78}$ Although we did not measure shear stress, we could not find any correlation between nitrate concentrations and haematocrit values that might have influenced viscosity/shear stress. Thus, NO synthase might be regulated mainly by pressure and blood flow in patients with VSD.

We have demonstrated that raised pulmonary pressure and blood flow might lead to upregulation of $\mathrm{NO}$ production in patients with VSD. Plasma nitrate concentrations decreased dramatically after surgery for VSD. These results support the concept that endothelia respond to intravascular or cardiac pressure with increased NO production. This represents a compensatory mechanism for high pulmonary pressure and the cardiohaemodynamics of VSD in children. Plasma nitrate might be a good marker of intravascular pressure and pulmonary blood flow.

This study was supported by a Grant-in-Aid for General Scientific Research (C) 07670919 from the Ministry of Education, Science, Sports and Culture of Japan, Research Grants from the Morinaga Hoshikai and the Mami Mizutani Foundation.

1 Barnes PJ. Nitric oxide and airways. Eur Resp f 1993;6:1635 .

2 Radomski MW, Palmer RMJ, Moncada S. An L-arginine/ nitric oxide pathway present in human platelets regulates aggregation. Proc Natl Acad Sci USA 1990;87:5193-7.

3 Pepke-Zaba J, Higenbottam TW, Dinh-Xuan AT, Stone D, monary hypertension. Lancet 1991;338:1173-4.
4 Balligand JL, Kelly RA, Marsden PA, Smith TW, Michel T. Control of cardiac muscle cell function by an endogenous nitric oxide signaling system. Proc Natl Acad Sci USA 1993;90:347-51

5 Amezcua JL, Palmer RMJ, Souza BM, Moncada S. Nitric oxide synthesized from L-arginine regulates vascular tone in the coronary circulation of the rabbit. $\mathrm{Br} \mathcal{F}$ Pharmacol 1991;97:1119-24.

6 Nava E, Noll G, Luscher TF. Increased activity of constitutive nitric oxide synthase in cardiac endothelium in spontaneous hypertension. Circulation 1995;91:2310-13.

7 Hattler BG, Oddis CV, Zeevi A, et al. Regulation of constiutive nitric oxide synthase activity by the human heart. $\mathrm{Am}$ 7 Cardiol 1995;76:957-9.

8 Nishida K, Harrison DG, Navas JP, et al. Molecular cloning and characterization of the constitutive bovine aortic endothelial cell nitric oxide synthase. F Clin Invest 1992;90: 2092-6.

9 Reddy VM, Wong J, Liddicoat JR, Johengen M, Chang R, Fineman JR. Altered endothelium-dependent vasoactive responses in lambs with pulmonary hypertension and increased pulmonary blood flow. Am f Physiol 1996;271: H562-70.

10 Black SM, Fineman JR, Johengen M, Bristow J, Soifer SJ. Increased pulmonary blood flow alters the molecular regulation of vascular reactivity in the lamb. Pediatr Res 1996;39:23A.

11 Wennmalm A, Benthin G, Edlund A, et al. Metabolism and excretion of nitric oxide in humans: an experimental study. Circ Res 1993;73:1121-7

12 Zeballos GA, Bernstein RD, Thompson CI, et al. Pharmacodynamics of plasma nitrate/nitrite as an indication of nitric oxide formation in conscious dogs. Circulation 1995; 91:2982-8.

13 Katz RW, Pollack MM, Weibley RE. Pulmonary artery cathterization in pediatric intensive care. Adv Pediatr 1984;30: eterization
$169-90$.

14 Lequime J. Cardiac output estimation to the Fick principle. Malattie Cardiovasculari 1966;7:169-71.

15 Godfrey K. Comparing the means of several groups. N Engl f Med 1985;313:1450-60.

16 Bridges ND, Freed MD. Cardiac catheterization. In: Emmanouilides GC, ed. Moss and Adams heart disease in infants, children, and adolescents. Baltimore: Williams and Wilkins, 1995:310-29.

17 Myles PS, Leong CK, Currey J. Endogenous nitric oxide and low systemic vascular resistance after cardiopulmonary bypass. F Cardiothorac Vasc Anesth 1997;11:571-4.

18 Iizuka T, Oishi K, Sasaki M, et al. Nitric oxide and aneurysm formation in Kawasaki disease. Acta Pediatr 1997;86:470-3. 